\title{
Waveguide Design for Long Wavelength InGaN Based Laser Diodes
}

\author{
G. Muziǫ ${ }^{a, *}$, H. Turski ${ }^{a}$, M. Siekacz ${ }^{a, b}$, M. SAwiCka $^{a, b}$, P. Wolny $^{a}$, \\ C. Cheze $^{b}$, G. Cywiński ${ }^{a}$, P. Perlin ${ }^{a, b}$ And C. Skierbiszewski ${ }^{a, b}$ \\ ${ }^{a}$ Institute of High Pressure Physics, Sokołowska 29/37, 01-142 Warsaw, Poland \\ ${ }^{b}$ TopGaN Ltd, Sokołowska 29/37, 01-142 Warszawa, Poland
}

\begin{abstract}
One-dimensional optical waveguide calculations were performed to study the dependence of waveguide design on confinement factor $(\Gamma)$ and optical losses $\left(\alpha_{i}\right)$ of nitride laser diodes for emission wavelength ranging from $405 \mathrm{~nm}$ to $520 \mathrm{~nm}$. We found that the conventional waveguide design containing GaN waveguide and AlGaN cladding layers known from violet laser diode does not support sufficient confinement of the optical mode for long wavelength devices $(\lambda>450 \mathrm{~nm})$. We proposed a new design consisting of a thick InGaN waveguide which enhances the confinement. We compared the theoretical predictions with laser diodes grown by plasma assisted molecular beam epitaxy.
\end{abstract}

PACS: 42.55.Px, 85.60.- q, 42.82.Et, 81.15.Hi

\section{Introduction}

Recently, the fabrication of nitride based laser diodes (LDs) with emission wavelength ranging from UV up to green became very intensively studied due to their potential impact on optoelectronics e.g. laser projectors, solid state lightening [1-3]. One of the key challenges in producing efficient InGaN based LDs is the waveguide design. There are some recent experimental works studying the influence of waveguide design on LD characteristics for wavelengths up to $440 \mathrm{~nm}$. Ryu et al. [4] showed the influence of $n$-AlGaN cladding composition on electrical properties of LDs. Strauss et al. [5] investigated the influence of thickness of $n$-AlGaN cladding on optical beam quality. There are also some theoretical works giving a survey in waveguide design for blue and green LDs [6, 7].

In this paper we use a one-dimensional optical waveguide model to study the properties of optical modes in separate confinement heterostructure violet, blue and green LDs. We show a drop of confinement factor with wavelength. We investigate the role of InGaN waveguide and propose it as a solution to compensate the drop. Results are compared with characteristics for LDs operating at $450 \mathrm{~nm}$ grown by plasma assisted molecular beam epitaxy (PAMBE).

\section{Method}

For the calculations we use a 1D transfer matrix method [8]. The refractive index model of AlGaN alloys is taken from Ref. [9]. Due to a lack of refractive index

\footnotetext{
* corresponding author; e-mail: gmuziol@unipress.waw.pl
}

data for InGaN, we apply the procedure of Bergmann and Casey [8] and shift the energy scale of GaN refractive index

$$
n_{\text {InGaN }}(x, E)=n_{\mathrm{GaN}}\left\{E-\left[E_{\mathrm{g}}(x)-E_{\mathrm{g}}(0)\right]\right\}
$$

with $E_{\mathrm{g}}(x)$ being the band gap energy of $\operatorname{In}_{x} \mathrm{Ga}_{1-x} \mathrm{~N}$ alloys [10]:

$$
E_{\mathrm{g}}(x)=3.42(1-x)+0.77 x-1.43 x(1-x) .
$$

The absorption coefficients used for the calculations are $125 \mathrm{~cm}^{-1}$ for electron blocking layer (EBL) and contact layer, $25 \mathrm{~cm}^{-1}$ for $\mathrm{Mg}$ doped layers, $10 \mathrm{~cm}^{-1}$ for $\mathrm{Si}$ and unintentionally doped layers [6]. Refractive index and absorption coefficient of $\mathrm{Au}$ have been taken from Ref. [11].

The confinement factor is defined as the ratio of the mode in the quantum wells (which is the part generating optical gain) and the mode integrated over the whole structure divided by number of quantum wells

$$
\Gamma=\frac{1}{N_{\mathrm{QW}}} \frac{\int_{\mathrm{QW}}|E(x)|^{2} \mathrm{~d} x}{\int_{-\infty}^{+\infty}|E(x)|^{2} \mathrm{~d} x} .
$$

Optical losses of $j$-th layer are defined as the product of the part of the mode in this layer and its absorption coefficient. The internal losses $\left(\alpha_{i}\right)$ are defined as sum of optical losses of all layers

$$
\alpha_{i}=\sum_{j} \frac{\int_{j}|E(x)|^{2} \mathrm{~d} x}{\int_{-\infty}^{+\infty}|E(x)|^{2} \mathrm{~d} x} \alpha_{j} .
$$

\section{Results and discussion}

In Fig. 1a we show a conventional laser structure emitting at $405 \mathrm{~nm}$. It consists of $2 \mu \mathrm{m} \mathrm{Al}_{0.05} \mathrm{Ga}_{0.95} \mathrm{~N}: \mathrm{Si}$ 
acting as $n$-type cladding layer, $100 \mathrm{~nm}$ GaN waveguide, an active region with three $3 \mathrm{~nm} \operatorname{In}_{0.12} \mathrm{Ga}_{0.88} \mathrm{~N}$ quantum wells (QW) and $5 \mathrm{~nm} \mathrm{GaN} \mathrm{quantum} \mathrm{barriers} \mathrm{(QB)}$ followed by $20 \mathrm{~nm}$ of $\mathrm{Al}_{0.15} \mathrm{Ga}_{0.85} \mathrm{~N}: \mathrm{Mg}^{+}$acting as EBL and a $100 \mathrm{~nm}$ GaN:Mg waveguide. Above upper waveguide, $0.6 \mu \mathrm{m} \mathrm{Al}_{0.05} \mathrm{Ga}_{0.95} \mathrm{~N}: \mathrm{Mg}$ p-type cladding layer and $60 \mathrm{~nm} \mathrm{GaN}: \mathrm{Mg}^{+}$heavily-doped contact layer are grown. The $p$-type contact is made from Ni/Au. The near-field distribution for the conventional structure is shown in Fig. 1b. One can see the optical mode confined around the active region with the highest refractive index.

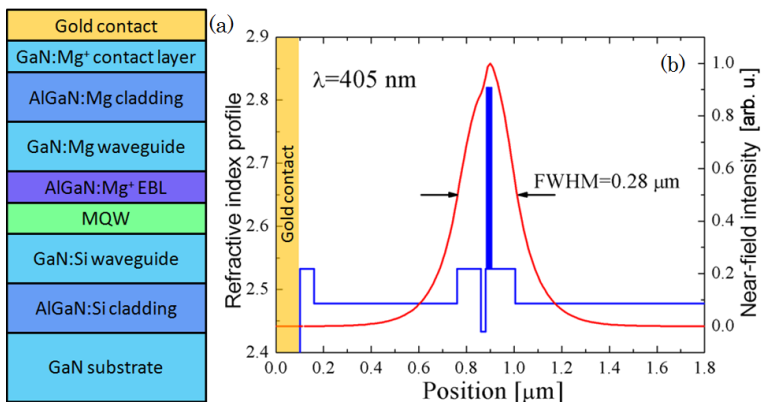

Fig. 1. (a) Conventional laser diode structure operating at $\lambda=405 \mathrm{~nm}$, (b) corresponding refractive index profile and distribution of optical mode.

The optical mode distribution for the conventional laser structure have been calculated for three different wavelengths: $405 \mathrm{~nm}, 455 \mathrm{~nm}, 520 \mathrm{~nm}$. Obtained confinement factors and full width at half maximum (FWHM) of near-field distribution are shown in Fig. 2. We see a striking drop of confinement factor with increasing wavelength which is correlated with increase in FWHM. As can be seen, the conventional LD structure does not provide sufficient $\Gamma$ for true-blue and green lasers. To overcome this problem Lermer et al. [12] proposed using AlInN lattice-matched to GaN with a much lower refractive index as cladding layers. However, challenges in AlInN growth together with high activation energies of $\mathrm{Si}$ and $\mathrm{Mg}$ dopants make this proposition difficult for practical realization.

In order to compensate the drop of confinement factor for longer wavelengths we propose an alternative solution - to introduce a thick InGaN waveguide. We calculated the optical mode distribution for a structure similar to the conventional LD but containing additional InGaN waveguides from both sides of the active region as shown in Fig. 3a. Dependence of confinement factor on thickness of $\operatorname{In}_{0.08} \mathrm{Ga}_{0.92} \mathrm{~N}$ layers is shown in Fig. $3 \mathrm{~b}$ for $455 \mathrm{~nm}$ and $520 \mathrm{~nm}$. We found that for a structure lasing at $455 \mathrm{~nm}$ to provide the same confinement factor as for the conventional violet LD (dashed line in Fig. 3b) one has to use $2 \times 55 \mathrm{~nm}$ of $\mathrm{In}_{0.08} \mathrm{Ga}_{0.92} \mathrm{~N}$. In case of $\mathrm{LD}$ lasing at $520 \mathrm{~nm}$ it is impossible to provide the same confinement factor with the use of InGaN waveguide of reasonable composition and thickness. To obtain $\Gamma=0.9 \%$

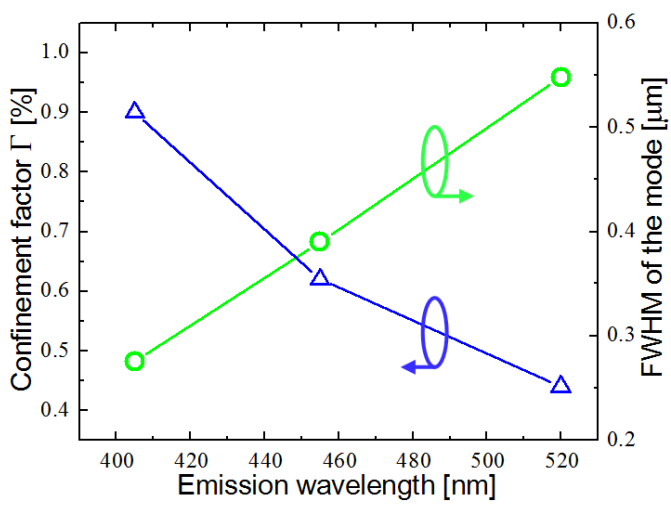

Fig. 2. Dependence of confinement factor and FWHM of near-field distribution on the wavelength for the conventional $\mathrm{LD}$ structure.

per QW for $\lambda=520 \mathrm{~nm}$ AlGaN claddings with higher $\mathrm{Al}$ content are required. We found that for $2 \times 50 \mathrm{~nm}$ of $\mathrm{In}_{0.15} \mathrm{Ga}_{0.85} \mathrm{~N}$ waveguide AlGaN claddings with $10 \%$ of $\mathrm{Al}$ are sufficient to provide the same confinement factor as the conventional LD structure for $\lambda=405 \mathrm{~nm}$.

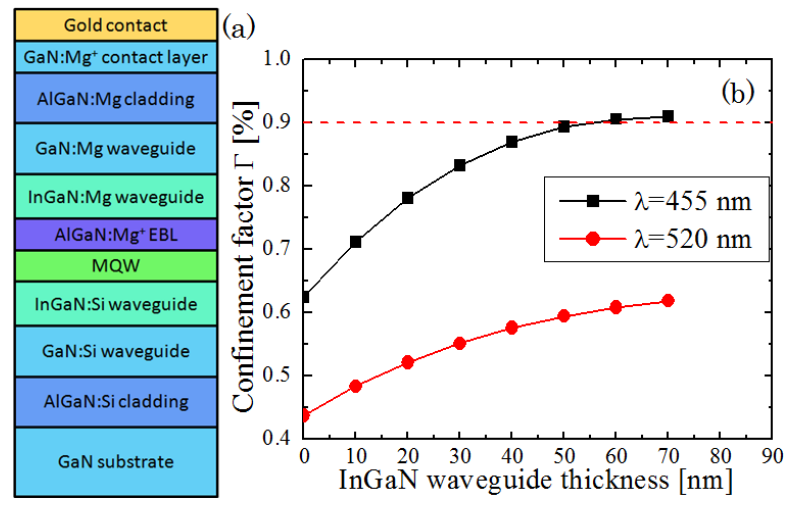

Fig. 3. (a) Laser structure with InGaN waveguides, (b) dependence of thickness of InGaN waveguide on confinement factor for blue and green LDs. The red dashed line indicates $\Gamma=0.9 \%$ for the conventional violet LD.

To link the confinement factor and optical losses with LDs parameters like threshold current density we consider the laser threshold condition given by

$$
\Gamma g_{\mathrm{th}}=\alpha_{i}+\alpha_{\mathrm{m}},
$$

where $g_{\mathrm{th}}$ is the threshold material gain, $\alpha_{i}$ and $\alpha_{\mathrm{m}}$ are internal and mirror losses, respectively. By increasing $\Gamma$ or by decreasing $\alpha_{i}$ one can reduce the threshold material gain which reduces the threshold current density for lasing.

To prove our theoretical findings we have grown two LDs (diode A and diode B) with different thickness of InGaN waveguide by PAMBE. Details of the growth and processing of these diodes can be found elsewhere [13]. Diode A consists of $2 \mu \mathrm{m} \mathrm{Al}_{0.045} \mathrm{Ga}_{0.955} \mathrm{~N}: \mathrm{Si}$ cladding, $100 \mathrm{~nm}$ GaN waveguide, $40 \mathrm{~nm}$ of additional 
$\mathrm{In}_{0.08} \mathrm{Ga}_{0.92} \mathrm{~N}$ waveguide, $3 \mathrm{~nm} \quad \mathrm{In}_{0.17} \mathrm{Ga}_{0.83} \mathrm{~N}$ single quantum well, $20 \mathrm{~nm} \operatorname{In}_{0.01} \mathrm{Al}_{0.15} \mathrm{Ga}_{0.84} \mathrm{~N}: \mathrm{Mg}^{+}$of EBL, $10 \mathrm{~nm}$ upper $\mathrm{In}_{0.08} \mathrm{Ga}_{0.92} \mathrm{~N}: \mathrm{Mg}$ waveguide, $80 \mathrm{~nm} \mathrm{GaN}$ waveguide, $250 \mathrm{~nm}$ of superlattice cladding with average composition of $\mathrm{Al}_{0.075} \mathrm{Ga}_{0.925} \mathrm{~N}: \mathrm{Mg}$ followed by $100 \mathrm{~nm}$ of another superlattice cladding $\operatorname{In}_{0.01} \mathrm{Al}_{0.075} \mathrm{Ga}_{0.915} \mathrm{~N}: \mathrm{Mg}$. The last layer is a $20 \mathrm{~nm} \operatorname{In}_{0.01} \mathrm{Ga}_{0.99} \mathrm{~N}: \mathrm{Mg}^{+}$contact layer. Diode B has a similar structure with three differences (i) $60 \mathrm{~nm} n$-type GaN waveguide instead of $100 \mathrm{~nm}$, (ii) $80 \mathrm{~nm}$ of $\operatorname{In}_{0.08} \mathrm{Ga}_{0.92} \mathrm{~N}$ waveguide instead of $40 \mathrm{~nm}$, (iii) $350 \mathrm{~nm}$ of $\mathrm{Al}_{0.075} \mathrm{Ga}_{0.925} \mathrm{~N}$ superlattice cladding instead of $250 \mathrm{~nm}$.

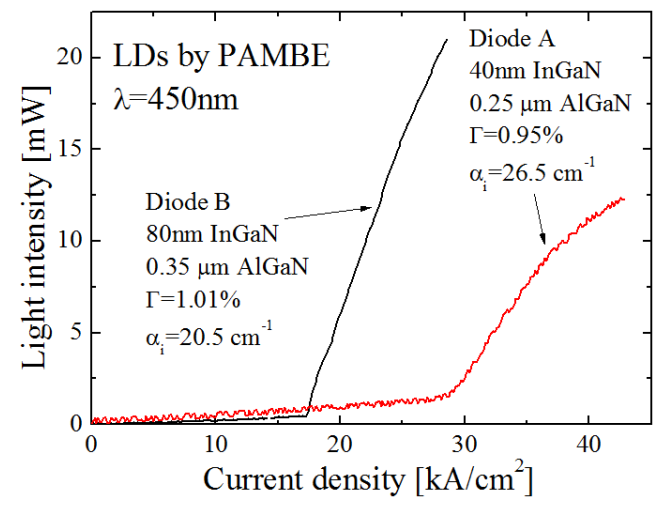

Fig. 4. $L-I$ characteristics measured in pulsed mode with $200 \mathrm{~ns}$ pulse width and $0.1 \%$ duty cycle.

\section{TABLE}

Calculated confinement factor $\Gamma$, internal losses $\alpha_{i}$ and losses in metal contact $\alpha_{\mathrm{Au}}$.

\begin{tabular}{c|c|c}
\hline \hline Parameter & Diode A & Diode B \\
\hline$\Gamma[\%]$ & 0.95 & 1.01 \\
$\alpha_{i}\left[\mathrm{~cm}^{-1}\right]$ & 26.5 & 20.5 \\
$\alpha_{\mathrm{Au}}\left[\mathrm{cm}^{-1}\right]$ & 7.3 & 1.4
\end{tabular}

The $L-I$ characteristics of these diodes are shown in Fig. 4. It is clearly seen that diode B with thicker InGaN waveguide and thicker AlGaN cladding has much lower threshold current and higher slope efficiency than diode A. In Table we present results of our calculations of $\Gamma, \alpha_{i}$ and optical losses in $\mathrm{Ni} / \mathrm{Au}$ contact for these structures. For diode B we found that thicker InGaN waveguide increases $\Gamma$ and lowers optical losses in $p$-type metal contact. To further decrease $\alpha_{\mathrm{Au}}$ we have introduced thicker AlGaN cladding in diode B.

\section{Conclusions}

We studied the differences of optical mode parameters for violet, blue and green InGaN based laser diodes.
We found a drop of confinement factor with increased light wavelength. We demonstrated that use of InGaN waveguides can compensate this decrease. We verified the theoretical predictions on two laser diodes grown by PAMBE with different waveguide design.

\section{Acknowledgments}

This work was supported partially by the Polish Ministry of Science and Higher Education grant No. IT 13426 and the European Union within European Regional Development Fund, through grant Innovative Economy (POIG.01.01.02-00-008/08).

\section{References}

[1] S. Nakamura, G. Fasol, S.J. Pearton, The Blue Laser Diode: The Complete Story, 2nd ed., Springer-Verlag, Heidelberg 2000.

[2] Y. Enya, Y. Yoshizumi, T. Kyono, K. Akita, M. Ueno, M. Adachi, T. Sumitomo, S. Tokuyama, T. Ikegami, K. Katayama, T. Nakamura, Appl. Phys. Exp. 2, 082101 (2009).

[3] A. Avramescu, T. Lermer, J. Muller, C. Eichler, G. Bruederl, M. Sabathil, S. Lutgen, U. Strauss, Appl. Phys. Exp. 3, 061003 (2010).

[4] H.Y. Ryu, K.H. Ha, J.K. Son, H.S. Paek, Y.J. Sung, K.S. Kim, H.K. Kim, Y. Park, S.N. Lee, O.H. Nam, J. Appl. Phys. 105, 103102 (2009).

[5] U. Strauss, C. Eichler, C. Rumbolz, A. Lell, S. Lutgen, S. Tautz, M. Schillgalies, S. Brüninghoff, Phys. Status Solidi C 5, 2077 (2008).

[6] C. Huang, Y. Lin, A. Tyagi, A. Chakraborty, H. Ohta, J.S. Speck, S.P. DenBaars, S. Nakamura, J. Appl. Phys. 107, 023101 (2010).

[7] L.Q. Zhang, D.S. Jiang, J.J. Zhu, D.G. Zhao, Z.S. Liu, S.M. Zhang, H. Yang, J. Appl. Phys. 105, 023104 (2009).

[8] M.J. Bergmann, H.C. Casey Jr., J. Appl. Phys. 84, 1196 (1998).

[9] G.M. Laws, E.C. Larkins, I. Harrison, C. Molloy, D. Somerford, J. Appl. Phys. 89, 1108 (2001).

[10] J. Wu, W. Walukiewicz, K.M. Yu, J.W. Ager, E.E. Haller, H. Lu, W.J. Schaff, Appl. Phys. Lett. 80, 4741 (2002).

[11] E.D. Palik, Handbook of Optical Constants of Solids, Academic Press, Boston 1985.

[12] T. Lermer, M. Schillgalies, A. Breidenassel, D. Queren, C. Eichler, A. Avramescu, J. Muller, W. Scheibenzuber, U. Schwarz, S. Lutgen, U. Strauss, Phys. Status Solidi A 207, 1328 (2010).

[13] C. Skierbiszewski, M. Siekacz, H. Turski, G. Muzioł, M. Sawicka, A. Feduniewicz-Żmuda, J. Smalc-Koziorowska, P. Perlin, S. Grzanka, Z.R. Wasilewski, R. Kucharski, S. Porowski, J. Vac. Sci. Technol. B 30, $02 \mathrm{~B} 102$ (2012). 